\title{
Modified PCI Multipliers for Time-Dependent Deformation of PSC Bridges
}

\author{
Joo-Ha Lee $\mathbb{D}^{1},{ }^{1}$ Kwang-Mo Lim, ${ }^{1}$ and Chan-Gi Park $\mathbb{D I D}^{2}$ \\ ${ }^{1}$ Department of Civil and Environmental Engineering, The University of Suwon, Hwaseong 18323, Republic of Korea \\ ${ }^{2}$ Department of Rural Construction Engineering, Kongju National University, Yesan 32439, Republic of Korea
}

Correspondence should be addressed to Chan-Gi Park; cgpark@kongju.ac.kr

Received 28 February 2018; Revised 14 May 2018; Accepted 23 May 2018; Published 10 July 2018

Academic Editor: Constantin Chalioris

Copyright (c) 2018 Joo-Ha Lee et al. This is an open access article distributed under the Creative Commons Attribution License, which permits unrestricted use, distribution, and reproduction in any medium, provided the original work is properly cited.

\begin{abstract}
Nowadays prestressed concrete (PSC) bridges have become very common, but there are still many difficulties in predicting their longterm behavior. In order to predict the long-term behavior of PSC bridges, it is possible to use very complex formulas developed by various researchers or numerical analysis through computer, but many engineers are having difficulty in using such methods. Moreover, the accuracy of the prediction result is not satisfactory compared to the effort. On the contrary, the PCI Bridge Design Manual proposes a method that can easily predict the long-term behavior using multipliers. However, this method does not take into account various construction schedules and has some assumptions that are inadequate for the current situation in various girder sections and topping thicknesses. Therefore, in this study, new long-time factors were developed by modifying the multipliers of the PCI Bridge Design Manual by a rational manner. This allows prediction of long-term behavior of bridges taking into account various construction schedules and the characteristics of modern girder sections. The prediction results of the long-term camber and deflection of PSC bridges using the proposed multipliers were compared with those using the basic PCI Bridge Design Manual, the improved PCI Bridge Design Manual, KR C-08090 (same as ACI 318-14), and numerical analysis. As a result, the newly proposed method makes possible to predict the long-term behavior at any time after casting, and the accuracy of the prediction is also improved.
\end{abstract}

\section{Introduction}

Recently, the application of prestressed concrete (PSC) bridges has been increasing due to the development of highstrength concrete, the improvement of strength and quality of prestressing (PS) steel, and the development of structural analysis technology using computer program. The long-term behavior of these PSC bridges is very important because it directly affects the serviceability and safety of the bridge. In the case of high-speed railway, for example, very small deflection of the railway caused by the long-term deformation of the bridge can cause serious problems on the running ability and safety of train. Therefore, it is necessary to accurately predict the time-dependent deformation in the design and construction stages and even use stage of the bridge. However, it is very difficult to accurately calculate time-dependent deformation of PSC bridges. The calculations should take into account creep and shrinkage as well as load-induced deformation, which can cause significant deformation over the years. Especially, unlike nonprestressed members, for prestressed members, prestress forces and prestress losses must be considered. In addition, when combined with nonprestressed members, the prediction of long-term behavior becomes more difficult.

Korea's railway design guidelines and handbooks (KR C-08090) provides a factor, $\lambda$, applied to initial deflection for estimating the additional long-term deflection of nonprestressed reinforced concrete members as shown in the following equation:

$$
\lambda=\frac{\xi}{1+50 \rho^{\prime}},
$$

where $\rho^{\prime}$ is the ratio of compressive reinforcement and $\xi$ is the time-dependent factor for sustained loads to be equal to 2.0 for 5 years or more, 1.4 for 12 months, 1.2 for 6 months, and 1.0 for 3 months. 
Table 1: PCI Bridge Design Manual basic multipliers [18]. Without composite topping With composite topping

At erection

(1) Deflection (downward) component-apply to the

elastic deflection due to the member weight at

1.85

1.85

transfer of prestress

(2) Camber (upward) component-apply to the

elastic camber due to prestress at the time of transfer

of prestress

Final

(3) Deflection (downward) component-apply to the

elastic deflection due to the member weight at

transfer of prestress

(4) Camber (upward) component-apply to the

elastic camber due to prestress at the time of transfer

of prestress

(5) Deflection (downward) - apply to elastic

deflection due to superimposed dead load only

(6) Deflection (downward) - apply to elastic

deflection caused by the composite topping

It should be noted that (1) of KR C-08090 [1] actually comes from the equation presented by ACI 318-14 [2]. The ACI 318 code [2] is primarily for building applications, not for bridges. Moreover, both KR C-08090 [1] and ACI 318-14 [2] do not provide specific design guideline such as prediction equations for long-term behavior of PSC members. The ACI 318-14 [2] merely suggests an abstract guideline that additional time-dependent deflections of PSC members can be calculated by considering the stresses of concrete and steel bars under sustained load, the creep and shrinkage effects of concrete, and the relaxation of PS steels.

Alternatively, the long-term deflection of PSC bridges can be calculated by using the concrete creep coefficient and drying shrinkage formulas given in various standards [3-5]. However, such formulas are somewhat complicated to use in practice because they need to take into consideration various parameters including concrete mix proportion and surrounding environment. They also do not fully account for the effects and losses of the prestress. Moreover, even through these complex methods, there is no guarantee of highly accurate predictions.

Until recently, many researchers have proposed various methods to predict the long-term behavior of PSC bridges [6-11]. However, the reliability of such predictions has not been sufficiently verified, and these methods are difficult and complicated for designers to understand and use. In addition, due to recent advances in computer technology, many researchers are trying to predict and evaluate the long-term behavior of PSC bridges by numerical analysis using the finite difference method or finite element method [12-17], but for designers, a simple and clear prediction method is more preferable.

On the contrary, the PCI Bridge Design Manual [18] presents multipliers that can be easily used to predict longterm deformation of PSC bridges. However, in the PCI Bridge Design Manual [18], the multipliers can be applied only to two points of time, erection and final. In practice, the timing of the girder construction of PSC bridges can vary greatly depending on the site conditions, and the long-term deflection should be checked out at any important time in addition to the time of erection and final depending on various construction plans and processes. Furthermore, since the PCI Bridge Design Manual [18] multipliers are based on the 1977 Martin's study [19], it is difficult to say that they properly reflect the characteristics of various cross sections of modern PSC bridges.

Therefore, in this study, modified PCI multipliers for longterm deflection of PSC bridges considering various construction schedules and cross sections of modern PSC bridges were proposed so that the time-dependent deformation of PSC bridges can be more easily and accurately predicted.

\section{PCI Bridge Design Manual Basic Multipliers}

Table 1 shows the basic multipliers presented in the PCI Bridge Design Manual [18] for predicting long-term cambers and deflections of PSC members. Derivation of these multipliers is in [19].

In (1), for the nonprestressed concrete, the base factor for additional long-term deflection, $\mu_{\mathrm{b}}$, is 2.0 in the absence of compressive reinforcement. For PSC members, however, since the elastic deflection due to member weight at the release of the prestress, not at the standard age of 28 days, is multiplied by the long-time factor, the factor should be calculated considering the elastic modulus $E_{\mathrm{ci}}$ at the time of release, not the elastic modulus $E_{\mathrm{c}}$ at 28 days, as follows:

$$
\mu_{\mathrm{df}}=\frac{E_{\mathrm{ci}}}{E_{\mathrm{c}}} \mu_{\mathrm{b}} \text {. }
$$

Since $E_{\mathrm{ci}}$ is about $85 \%$ of $E_{\mathrm{c}}$ and $\mu_{\mathrm{b}}$ is 2.0 , (2) would then become $\mu_{\mathrm{df}}=1.7$. As shown in Table 1, therefore, the multiplier for deflection at final is $1+\mu_{\mathrm{df}}=2.7$.

In the PCI Bridge Design Manual [18], it is assumed that the period from casting to erection is about 30-60 days, and in this period, creep and drying shrinkage, which are the main factors of the long-term behavior, will have reached about 40 to $60 \%$ of the ultimate value. Using the average 
TABle 2: PCI Bridge Design Manual improved multipliers [20].

\begin{tabular}{|c|c|c|c|c|}
\hline \multirow{2}{*}{ Load condition } & \multicolumn{2}{|c|}{ Erection time } & \multicolumn{2}{|c|}{ Final time } \\
\hline & Formula & Average & Formula & Average \\
\hline Initial prestress & $1+C_{\mathrm{a}}$ & 1.96 & $1+C_{\mathrm{u}}$ & 2.88 \\
\hline Prestress loss & $\alpha_{\mathrm{a}}\left(1+\chi C_{\mathrm{a}}\right)$ & 1.00 & $\left(1+\chi C_{u}\right)$ & 2.32 \\
\hline Self-weight & $1+C_{a}$ & 1.96 & $1+C_{\mathrm{u}}$ & 2.88 \\
\hline Dead load on plain beam & 1.00 & 1.00 & $1+C_{\mathrm{u}}^{\prime}$ & 2.50 \\
\hline Dead load on composite beam & 1.00 & 1.00 & $1+C_{\mathrm{u}}^{\prime}$ & 2.50 \\
\hline
\end{tabular}

$C_{\mathrm{u}}=$ ultimate creep coefficient for loads applied immediately after transfer, and the average value is $1.88 . C_{\mathrm{u}}^{\prime}=$ ultimate creep coefficient for loads applied at time of erection, and the average value is $1.50 . C_{\mathrm{a}}=$ creep coefficient for loading applied immediately after transfer and strains measured at time of erection, and the average value is $0.96 . \alpha_{\mathrm{a}}=$ time-dependent prestress loss at erection divided by total time-dependent prestress loss, and the average value is 0.60 . $\chi=$ Bazant's aging coefficient, and the average value is 0.70 .

value of $50 \%$, therefore, the long-term deflection coefficient at erection is presented as the following equation:

$$
1+\mu_{\mathrm{de}}=1+0.5 \mu_{\mathrm{df}}
$$

The multiplier for deflection at erection would then be $1+0.5(1.7)=1.85$.

In deriving the multiplier for the camber in the PCI Bridge Design Manual [18], the prestress loss is taken into account. That is, the method of obtaining the long-term camber by multiplying the long-time factor by the elastic camber at the release of the prestress is the same as (2), but considering the prestress loss, which is a phenomenon in which the prestress as a sustained load decreases over time. The long-term prestress loss is assumed to be $15 \%$ of the initial force. Therefore, using $\mu_{\mathrm{df}}$ in (2), factor for final longtime camber can be expressed as follows:

$$
\mu_{\mathrm{pf}}=\mu_{\mathrm{df}} \frac{P}{P_{0}} .
$$

Therefore, the multiplier used to determine the camber due to prestress is $1+\mu_{\mathrm{pf}}=1+1.7(0.85)=2.45$.

The multiplier for the camber due to prestress at the time of erection is derived in the same way as (3) is derived. The long-term loss of prestress is governed by long-term behavior factors such as creep and shrinkage of concrete. So, if these long-term behavior factors occur $50 \%$ of ultimate at erection, prestress loss will also result in one-half of the longtime total loss 15\%. Applying this to (4), the multiplier for the camber caused by the prestress at the time of erection can be calculated as follows:

$$
1+\mu_{\mathrm{pe}}=1+\mu_{\mathrm{de}}(1-0.15 \times 0.50) .
$$

Therefore, the multiplier applied to the initial upward camber caused by prestressing force is equal to be $1+\mu_{\mathrm{pe}}=1+0.85(0.925) \approx 1.80$.

Since the long-term deflection due to the superimposed sustained dead load depends on the creep, the multiplier is expressed by the following equation using the basic factor $\mu_{\mathrm{b}}=2.0$ :

$$
1+\mu_{\mathrm{sdf}}=1+2 \cdot 0=3.0 .
$$

In addition, the PCI Bridge Design Manual [18] provides multipliers for composite members by taking into account the effect of increased moment of inertia due to topping. As shown in the following equations, the effect of topping on the deflection and camber is taken into account by multiplying the difference between long-time factors at erection and final by the ratio of noncomposite to composite moments of inertia, $I_{\mathrm{o}} / I_{\mathrm{c}}$ :

$$
\begin{aligned}
& \mu_{\mathrm{dfc}}=\mu_{\mathrm{de}}+\left(\mu_{\mathrm{df}}-\mu_{\mathrm{de}}\right)\left(\frac{I_{\mathrm{o}}}{I_{\mathrm{c}}}\right), \\
& \mu_{\mathrm{pfc}}=\mu_{\mathrm{pe}}+\left(\mu_{\mathrm{pf}}-\mu_{\mathrm{pe}}\right)\left(\frac{I_{\mathrm{o}}}{I_{\mathrm{c}}}\right) .
\end{aligned}
$$

Here the PCI Bridge Design Manual [18] assumes that the section becomes composite at about the time of erection. The thickness of the topping is assumed to be 2 inches, and the value of $I_{\mathrm{o}} / I_{\mathrm{c}}$ is assumed to be 0.65 for commonly used members. Therefore, if these values are substituted in (7 and 8), the multiplier for deflection and camber of the composite member with topping is 2.40 and 2.20, respectively, as shown in Table 1 .

\section{PCI Bridge Design Manual Improved Multipliers}

As shown in Table 2, the PCI Bridge Design Manual, 2nd Edition [20], suggested an improved multiplier method proposed by Tadros et al. [21]. This method is very similar to the basic multiplier method described in the preceding section. According to the manual, however, this method provides two improvements. First, it provides more accurate coefficients for cases where the reliable creep coefficient is known or highperformance concrete with a very low creep coefficient is used. Second, the prediction of the deflection caused by the prestress loss can be calculated by considering the amount of prestress loss actually occurred. However, it is not easy to know the correct creep coefficient and the actual prestress loss at the design stage. Moreover, there are many variables that must be calculated separately to derive the multiplier, which is somewhat inconvenient for designers to use. However, since the average value is presented, it can be used effectively. It is noted that the improved multiplier method has been deleted in the current PCI Bridge Design Manual, 3rd Edition [18].

\section{Development of Proposed Multipliers}

4.1. Modification of PCI Multipliers for Prediction at Any Time. As mentioned earlier, the PCI Bridge Design Manual [18] provides multipliers only for at the time of erection and final. 


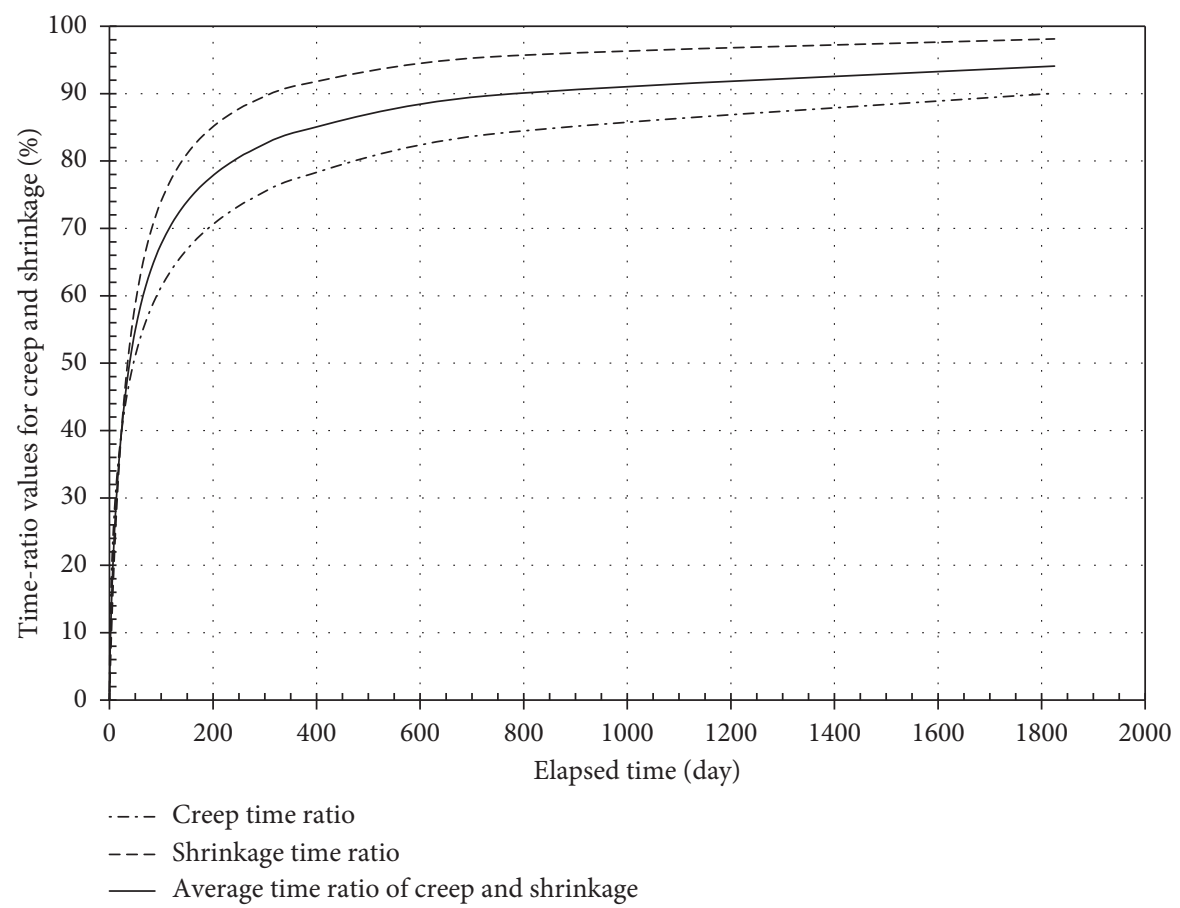

FIGURE 1: Rate of creep and drying shrinkage over time.

Moreover, it is assumed that the erection time is about 30-60 days after casting. In practice, however, the time of erection is very flexible depending on the site conditions. Therefore, in this study, the multipliers applicable at any time including the various time of erection were suggested by considering the rate of creep and drying shrinkage. It can be useful for field construction management and maintenance of structures, if the camber or deflection can be predicted at any time after casting.

Equations (3) and (5) were modified using $r_{t}$, the rate of creep, and drying shrinkage over time:

$$
\begin{aligned}
& 1+\mu_{\mathrm{dt}}=1+r_{t} \times \mu_{\mathrm{df}}, \\
& 1+\mu_{\mathrm{pt}}=1+\mu_{\mathrm{dt}}\left(1-0.15 \times r_{t}\right),
\end{aligned}
$$

where $t$ is the time after casting and $\mu_{\mathrm{dt}}$ and $\mu_{\mathrm{pt}}$ are the factors for time-dependent deflection and camber at the time of $t$ applied to initial deformation caused by member weight and prestressing force, respectively. $\mu_{\mathrm{df}}$ is 1.7 as in the PCI Bridge Design Manual [18]. If the time of the erection is $t(e)$, the multiplier for the deflection and camber at erection can be expressed by substituting $t(e)$ in (9) and (10) as follows:

$$
\begin{aligned}
& 1+\mu_{\mathrm{dt}(e)}=1+r_{t(e)} \times \mu_{\mathrm{df}}, \\
& 1+\mu_{\mathrm{pt}(e)}=1+\mu_{\mathrm{dt}(e)}\left(1-0.15 \times r_{t(e)}\right) .
\end{aligned}
$$

Also, the multiplier for the long-term deflection due to the superimposed dead load at any time can be expressed by the following equation:

$$
1+\mu_{\mathrm{sdt}}=1+r_{[t-t(\mathrm{~s})]} \times \mu_{\mathrm{sdf}},
$$

where $\mu_{\text {sdt }}$ is the factor for additional long-time deflection at time, $t$, applied to initial deflection caused by superimposed dead load and $t(s)$ is the time at which the superimposed dead load is applied. $\mu_{\text {sdf }}$ is 2.0 as in the PCI Bridge Design Manual [18].

The creep and drying shrinkage predictions presented in ACI 209R-92 [3] were used to calculate the rate of creep and shrinkage over time, $r_{t}$. For creep and shrinkage under standard condition, the relationship between at any time and at final is given by (13) and (14), respectively.

$$
\begin{gathered}
v_{t}=\frac{t^{0.6}}{10+t^{0.6}} v_{\mathrm{u}} \\
\left(\varepsilon_{\mathrm{sh}}\right)_{t}=\frac{t}{35+t}\left(\varepsilon_{\mathrm{sh}}\right)_{\mathrm{u}},
\end{gathered}
$$

where $t=$ time in days, $v_{t}=$ creep coefficient at any time, $v_{\mathrm{u}}=$ ultimate creep coefficient, $\left(\varepsilon_{\mathrm{sh}}\right)_{t}=$ shrinkage strain at any time, and $\left(\varepsilon_{\mathrm{sh}}\right)_{u}=$ ultimate shrinkage strain.

Long-term behavior is both affected by creep and drying shrinkage at the same time. Therefore, $r_{t}$, the rate of creep and drying shrinkage over time, were derived from the average of (13) and (14) as shown in (15). Figure 1 shows the graphs of creep and drying shrinkage rates over time.

$$
r_{t}=\frac{1}{2}\left(\frac{t^{0.6}}{10+t^{0.6}}+\frac{t}{35+t}\right) .
$$

4.2. Modification of Multipliers for Composite Member. As mentioned earlier, in the PCI Bridge Design Manual [18], for the composite member, the thickness of the topping is assumed to be 2 inches, and the ratio of noncomposite to composite moments of inertia, $I_{\mathrm{o}} / I_{\mathrm{c}}$, is 0.65 for all cases regardless of the shape of cross section. However, given the variety of girder geometry and the recent bridge slab deck 


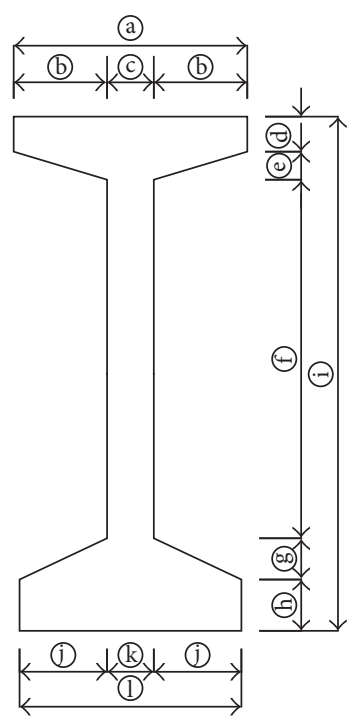

(a)

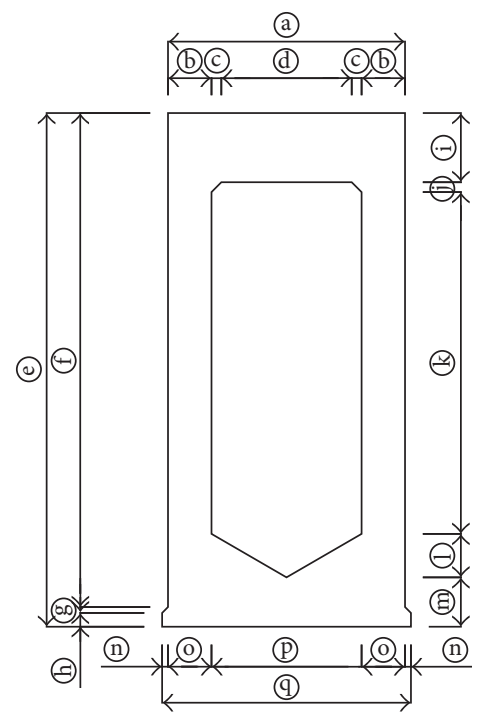

(b)

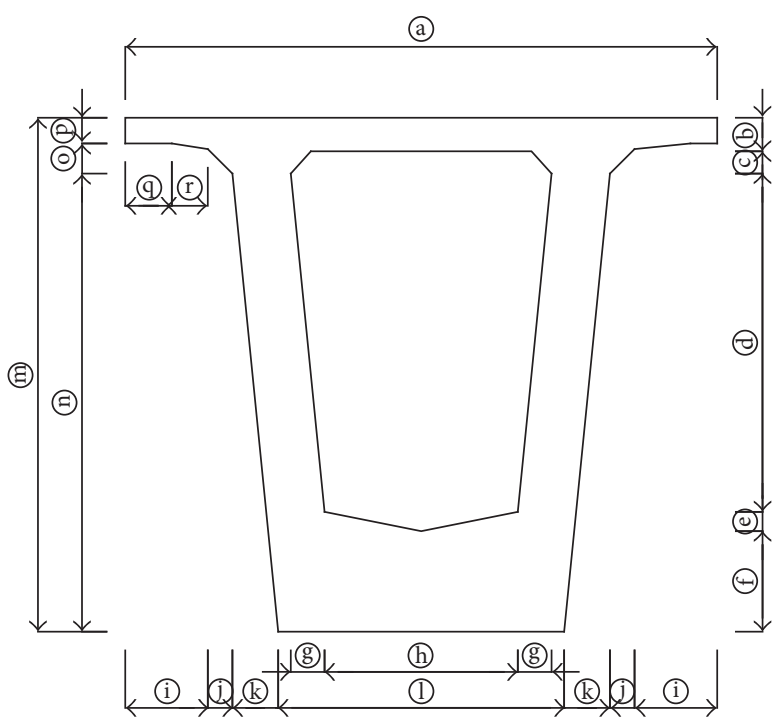

(c)

FIgUre 2: Typical cross sections of PSC bridges. (a) I girder; (b) box girder; (c) WPC girder.

TABle 3: Cross section dimension of I, box, and WPC girders by $\operatorname{span}(\mathrm{mm})$.

\begin{tabular}{lccccccccc}
\hline Type & \multicolumn{3}{c}{ I girder } & \multicolumn{3}{c}{ Box girder } & \multicolumn{3}{c}{ WPC girder } \\
Span & $25 \mathrm{~m}$ & $30 \mathrm{~m}$ & $35 \mathrm{~m}$ & $30 \mathrm{~m}$ & $35 \mathrm{~m}$ & $40 \mathrm{~m}$ & $30 \mathrm{~m}$ & $35 \mathrm{~m}$ & $40 \mathrm{~m}$ \\
\hline (a) & 1000 & 1000 & 1000 & 1200 & 1200 & 1200 & 3580 & 3580 & 2650 \\
(b) & 400 & 400 & 400 & 220 & 220 & 220 & 150 & 150 & 150 \\
(C) & 200 & 200 & 200 & 50 & 50 & 50 & 100 & 100 & 100 \\
(d) & 80 & 150 & 150 & 660 & 660 & 660 & 982 & 1135 & 1514 \\
() & 90 & 120 & 120 & 2000 & 2400 & 2600 & 116 & 115 & 86 \\
( & 1520 & 1550 & 1950 & 1900 & 2300 & 2500 & 350 & 500 & 450 \\
(9) & 240 & 180 & 180 & 30 & 30 & 30 & 98 & 113 & 151 \\
(b) & 320 & 200 & 200 & 70 & 70 & 70 & 1181 & 1150 & 865 \\
(1) & 2350 & 2200 & 2600 & 400 & 350 & 350 & 730 & 730 & 370 \\
(1) & 240 & 350 & 350 & 50 & 50 & 50 & 110 & 110 & 110 \\
() & 200 & 200 & 200 & 1080 & 1530 & 1730 & 145 & 175 & 205 \\
(1) & 680 & 900 & 900 & 220 & 220 & 220 & 1610 & 1550 & 1280 \\
(I) & - & - & - & 250 & 250 & 250 & 1700 & 2000 & 2300 \\
(A) & - & - & - & 30 & 30 & 30 & 1450 & 1750 & 2050 \\
() & - & - & - & 220 & 220 & 220 & 135 & 135 & 135 \\
(D) & - & - & - & 760 & 760 & 760 & 115 & 115 & 115 \\
(9) & - & - & - & 1260 & 1260 & 1260 & 480 & 480 & 120 \\
(1) & - & - & - & - & - & - & 250 & 250 & 250 \\
\hline
\end{tabular}

thickness, the assumptions for composite members in the PCI Bridge Design Manual [18] are not likely to reflect modern bridge characteristics. Therefore, in this study, the multipliers for the long-term behavior of composite member were proposed by analyzing the representative cross sections of the recent bridges.

Currently, girder sections commonly used in single-span railway bridges in Korea are I girder, box girder, and WPC (wide flange prestressed concrete). In general, a thickness of slab placed on the girder is $280 \mathrm{~mm}$. Figure 2 and Table 3 show the details of the cross sections of I girder, box girder, and WPC, which are the representative girder sections actually used in practice. Table 4 shows $I_{\mathrm{o}} / I_{\mathrm{c}}$ for all cross sections of Figure 2 and Table 3. As shown in Table 4, the value of $I_{\mathrm{o}} / I_{\mathrm{c}}$ is different from 0.65 of the PCI Bridge Design Manual [18]. $I_{\mathrm{o}} / I_{\mathrm{c}}$ was in the range of 0.51 to 0.56 , and box girder bridges and long span bridges tend to have relatively large $I_{\mathrm{o}} / I_{\mathrm{c}}$. For the convenience of design, this study proposed to use the total average value of 0.53 for $I_{\mathrm{o}} / I_{\mathrm{c}}$.

The PCI Bridge Design Manual [18] assumed that the section becomes composite at about the time of erection, but it is not always. Rather, there are many cases where topping is not applied when the girder is erected because of field condition and construction schedules. Therefore, multipliers have been proposed to enable the prediction of deflection and camber of the composite member at any time $t$ by considering the time, $t(c)$, at which the section becomes composite. This can be expressed as follows using (7)-(10):

$$
\begin{aligned}
& 1+\mu_{\mathrm{dtc}}=1+\mu_{\mathrm{dt}(\mathrm{c})}+\left(\mu_{d t}-\mu_{\mathrm{dt}(\mathrm{c})}\right)\left(\frac{I_{\mathrm{o}}}{I_{\mathrm{c}}}\right), \\
& 1+\mu_{\mathrm{ptc}}=1+\mu_{\mathrm{pt}(\mathrm{c})}+\left(\mu_{\mathrm{pt}}-\mu_{\mathrm{pt}(\mathrm{c})}\right)\left(\frac{I_{\mathrm{o}}}{I_{\mathrm{c}}}\right),
\end{aligned}
$$

where $I_{\mathrm{o}} / I_{\mathrm{c}}$ is 0.53 .

The factor for long-term deflection by a composite topping should be also modified by the ratio of $I_{\mathrm{o}} / I_{\mathrm{c}}$ because the elastic deflection caused by the placement of the topping, to which the factor is applied, is calculated using the noncomposite section as follows

$$
1+\mu_{\mathrm{tt}}=1+\mu_{\mathrm{sdt}}\left(\frac{I_{\mathrm{o}}}{I_{\mathrm{c}}}\right)
$$

where $\mu_{\mathrm{tt}}$ is the factor for additional long-term deflection caused by topping at any time, $t$.

As a result, the multipliers of the PCI Bridge Design Manual [18] in Table 1 were revised as shown in Table 5. 
TABLE 4: Ratio of noncomposite to composite moments of inertia by girder type and span.

\begin{tabular}{lccccc}
\hline Span & PCI Bridge Design Manual & I girder & Box girder & WPC girder & Average \\
\hline $25 \mathrm{~m}$ & & 0.51 & - & 0.51 \\
$30 \mathrm{~m}$ & 0.65 & 0.49 & 0.52 & 0.54 & 0.53 \\
$35 \mathrm{~m}$ & & - & 0.56 & 0.50 & 0.52 \\
$40 \mathrm{~m}$ & 0.65 & 0.51 & 0.57 & 0.54 & 0.53 \\
Average & & & 0.56 & 0.52 & $\mathbf{0 . 5 3}$ \\
\hline
\end{tabular}

Table 5: Proposed multipliers.

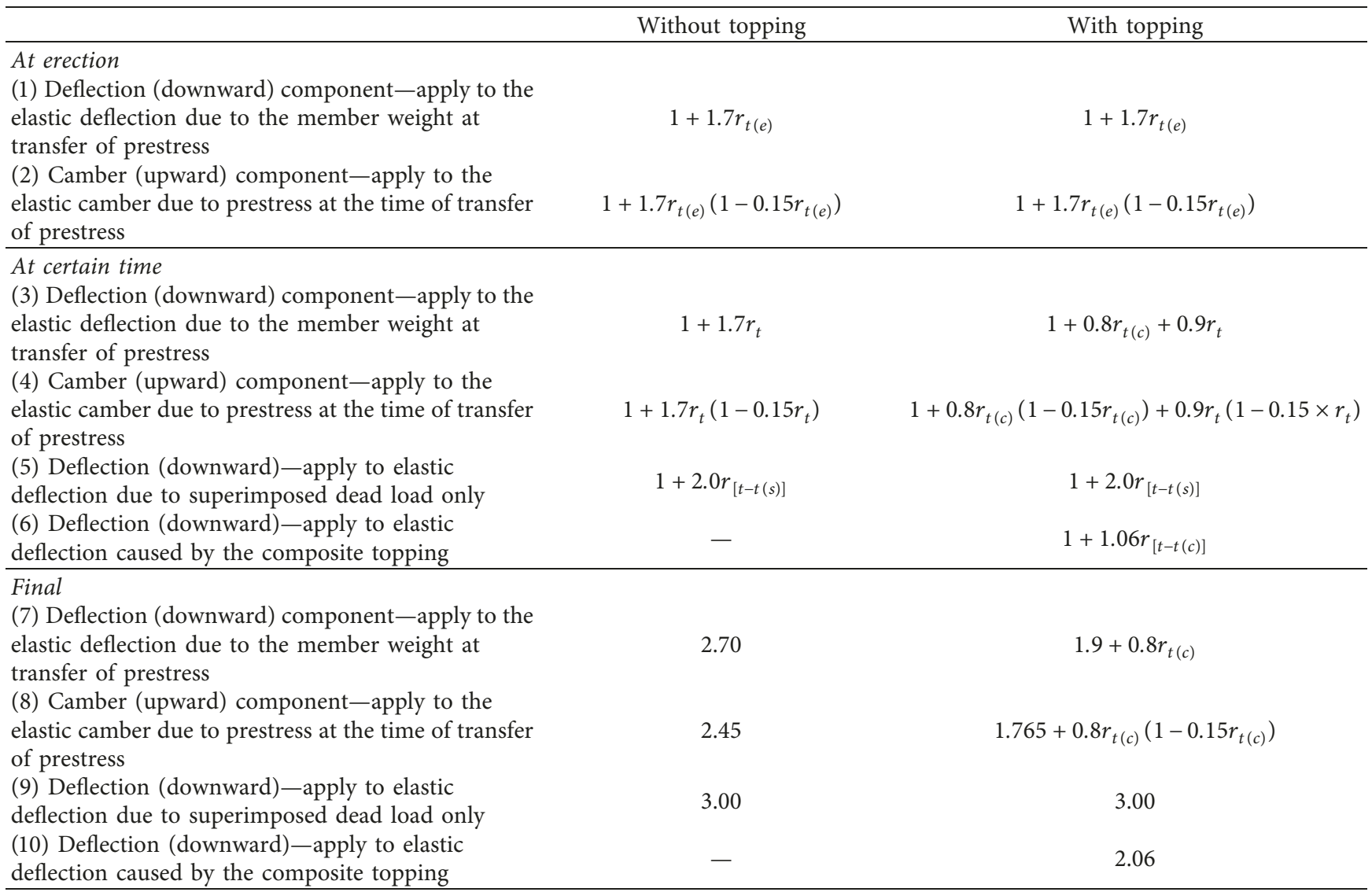

\section{Verification of Proposed Multipliers}

In order to verify the proposed multipliers, for actually constructed PSC bridges, the predictions of long-term camber and deflection by the proposed multipliers were compared with those by the basic PCI multipliers [18], the improved PCI multipliers [20], and KR C-08090 [1] (same as ACI 318-14 [2]). In addition, numerical analysis was performed, and the results were compared with the results from other prediction methods.

5.1. PSC Bridges for Verification. PSC bridges A and B, which were recently constructed on a new line from Wonju to Gangneung in Korea's high-speed railway, were selected to verify the prediction methods. Bridge A is a WPC type with a span of $38.8 \mathrm{~m}$, and bridge $B$ is constructed with an I-girder type with a span of $34 \mathrm{~m}$. The cross-sectional details of the bridges at midspan are shown in Figure 3. Tables 6 and 7 show the construction history of the bridges and the elastic deformation due to the applied load, respectively.

5.2. Numerical Analysis for Long-Term Behavior of PSC Bridges. Long-term behavior of the bridges A and B was predicted using MIDAS Civil, a general-purpose finite element analysis program. The validity of the MIDAS Civil has already been confirmed through previous researches [2224]. In general, the prediction of long-term behavior using a finite element analysis is known to have a higher accuracy than that of the methods using a multiplier such as the PCI Bridge Design Manual [18, 20], although the design convenience is poor [25-28]. Therefore, the numerical analysis results were used to verify the newly proposed multipliers.

The material model was selected from the database of the MIDAS Civil program. C40 and C27 were selected for the girder and deck concrete, respectively, and the strand of SWPC7B $\varnothing 15.2 \mathrm{~mm}$ was selected for PS steel. These 


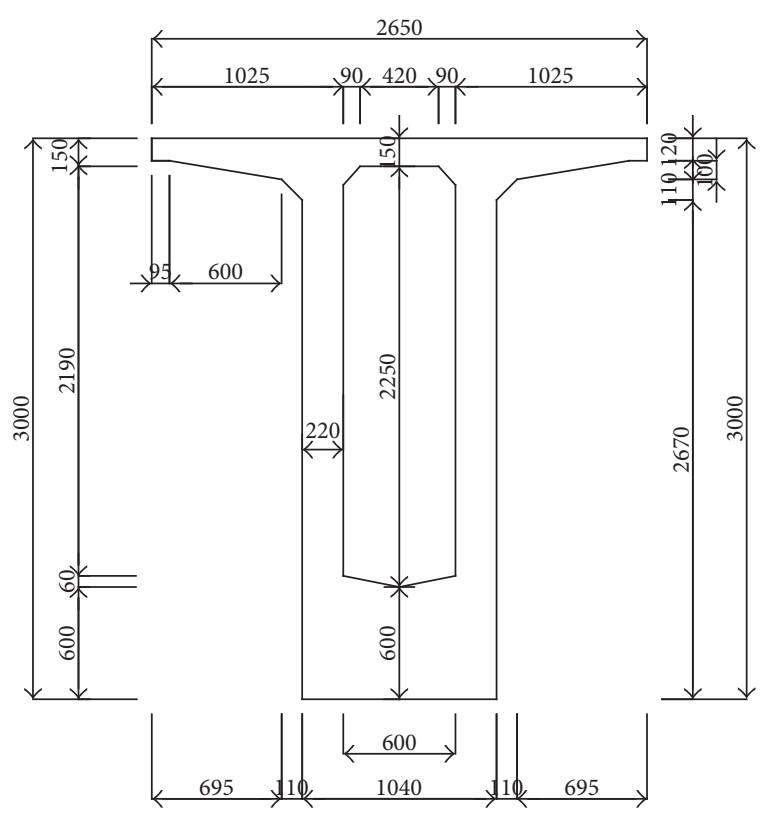

(a)

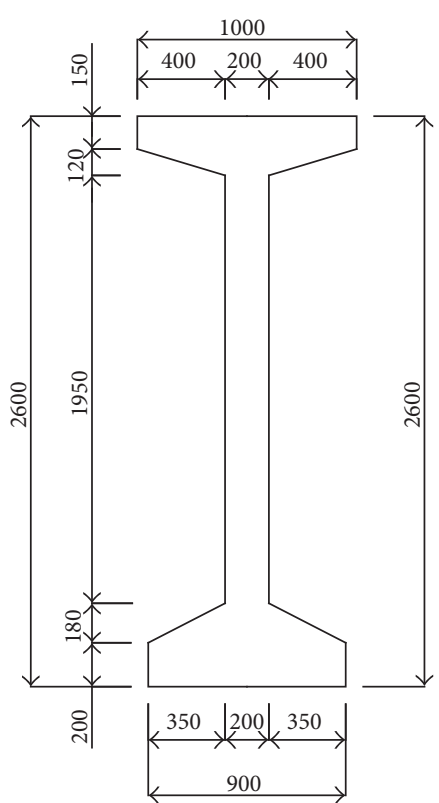

(b)

Figure 3: Cross-sectional details of bridges (a) A and (b) B.

materials are the same as concrete and PS steel actually used for bridges A and B. The structural members of the bridges were modeled based on structural calculations and design drawings of bridges $\mathrm{A}$ and $\mathrm{B}$. According to the design drawing, the strands were arranged by setting the actual coordinates of the strand on the girder nodes using the 3-D input type from tendon profile option of MIDAS Civil. The CEB-FIP MC90 model [5] was used to calculate creep and drying shrinkage of concrete. For the relaxation of the tendon, the Magura 45 model was used to consider the time-dependent loss of the prestress. Based on the construction history of the bridges A and B in Table 6, construction sequence analysis was carried out. After the cast of deck, composite behavior of the girder and the deck was simulated through the node connection using the rigid type of elastic link. In the same way, common duct which is the additional superimposed dead load was also simulated for composite behavior after its installation. At the final stage, the deformation patterns of bridges $A$ and $B$ are shown in Figure 4. As a result, the bridges A and B in the midspan showed $32.4 \mathrm{~mm}$ and $39.3 \mathrm{~mm}$ of camber at girder erection and $29.7 \mathrm{~mm}$ and $19.2 \mathrm{~mm}$ of camber at final, respectively.

\subsection{Comparison of Predictions of Long-Term Deformation.} Tables 8 and 9 and Figure 5 show the predictions of the longterm deformation of bridges $\mathrm{A}$ and $\mathrm{B}$ by using the proposed multipliers, the basic PCI multipliers [18], the improved PCI multipliers [20], KR C-08090 [1], and numerical analysis. For the improved PCI multipliers [20], the average values in Table 2 were used because the actual creep coefficient and the amount of the prestress loss can hardly be known.

Although the values of predictions by the proposed multipliers and KR C-08090 [1] were somewhat different
TABle 6: Construction history of bridges A and B.

\begin{tabular}{lcc}
\hline \multirow{2}{*}{ Event } & \multicolumn{2}{c}{ Time from casting (days) } \\
& Bridge A & Bridge B \\
\hline (1) Release & 1 & 1 \\
(2) Erection $(t(e))$ & 30 & 150 \\
(3) Topping $(t(c))$ & 240 & 157 \\
(4) 1st random time $(t 1)$ & 270 & 180 \\
(5) Superimposed dead load $(t(s))$ & 390 & 360 \\
(6) 2nd random time $(t 2)$ & 700 & 1000 \\
(7) Final & 5 years or & 5 years or \\
& more & more \\
\hline
\end{tabular}

TABLe 7: Elastic camber and deflection of bridges A and B.

\begin{tabular}{lcc}
\hline \multirow{2}{*}{ Load } & \multicolumn{2}{c}{ Camber $(+)$ or deflection $(-)$} \\
& Bridge A & Bridge B \\
\hline Self-weight & -22.3 & -16.5 \\
Prestressing force & +46.1 & +35.3 \\
Topping & -8.0 & -7.5 \\
Superimposed dead load & -2.5 & -2.65 \\
\hline
\end{tabular}

from the prediction by numerical analysis, their prediction trends of the camber over time were generally similar because they provided available multipliers at any time. In the case of the basic PCI multipliers [18], however, the longterm behavior after the erection was quite different from other prediction methods because there are no applicable long-term factors for the period between the erection and the final.

The girder of bridge A was erected on the 30th day after casting, while the girder of bridge B was erected on the 150th day, relatively long time after casting. The basic PCI 

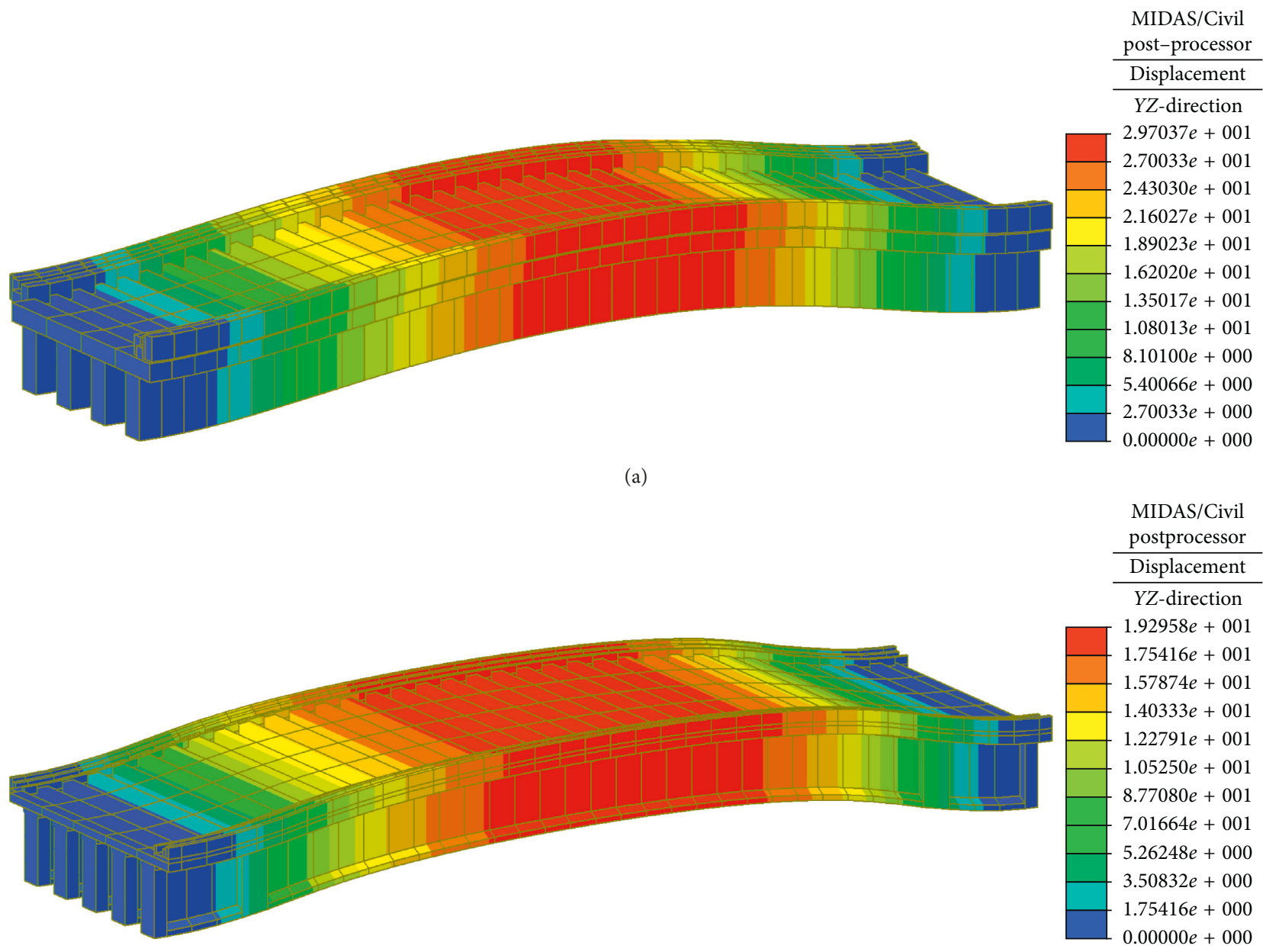

(b)

Figure 4: Analysis result of final deformation of bridges (a) A and (b) B.

multiplier method [18] calculated the long-term camber using the same multiplier for both bridges regardless of the different erection time, while the new proposed method used different long-term multipliers for the bridges $\mathrm{A}$ and $\mathrm{B}$ in order to consider different creep and shrinkage rates. As a result, the predictions at erection by the proposed method were smaller for bridge A and larger for bridge B than those by the basic PCI multiplier method [18], as shown in Figure 5.

In terms of the long-term behavior after erection, the camber predicted by KR C-08090 [1] was generally the largest among all prediction methods. KR C-08090 [1] does not take into account prestress loss, so it overestimates the camber by prestress force. The predictions by the proposed method were larger than the predictions by numerical analysis until about 200 days after superimposed dead load was applied, and thereafter, they were smaller than the predictions by numerical analysis.

When comparing the camber at final, the predictions were large in the order of KR C-08090 [1], numerical analysis, proposed method, improved PCI multipliers [20], and basic PCI multipliers [18] for both bridges A and B. Numerical analysis seems to estimate the effect of creep and shrinkage on long-term deformation weaker than other methods. In comparison with numerical analysis for deformation at the final, difference rates of the proposed method, basic PCI multipliers [18], improved PCI multipliers [20], and KR C-08090 [1] were 10.1\%, 25.9\%, 11.6\%, and $34.3 \%$ for bridge $\mathrm{A}$, respectively, and $14.6 \%, 33.1 \%$, $14.3 \%$, and $35.0 \%$ for bridge $\mathrm{B}$, respectively. It is interesting to note that the proposed formula and the improved PCI multiplier method [20] show very similar prediction results of ultimate deformation at final.

Figure 6 shows the long-term behavior predicted by the proposed multipliers for each load type. In early ages, a relatively large amount of camber was observed due to the prestress, but as time went by, the rate of increase of camber by prestress decreased sharply because the amount of creep and drying shrinkage converged and the PS steel relaxation increased. The amount of deflection due to self-weight was smaller than the camber due to the prestress, but the tendency of deflection over time was very similar to that of camber. On the contrary, after the girder erection, a considerable amount of immediate deflection and long-term deflection due to dead loads such as topping and common duct partially offset the camber. 


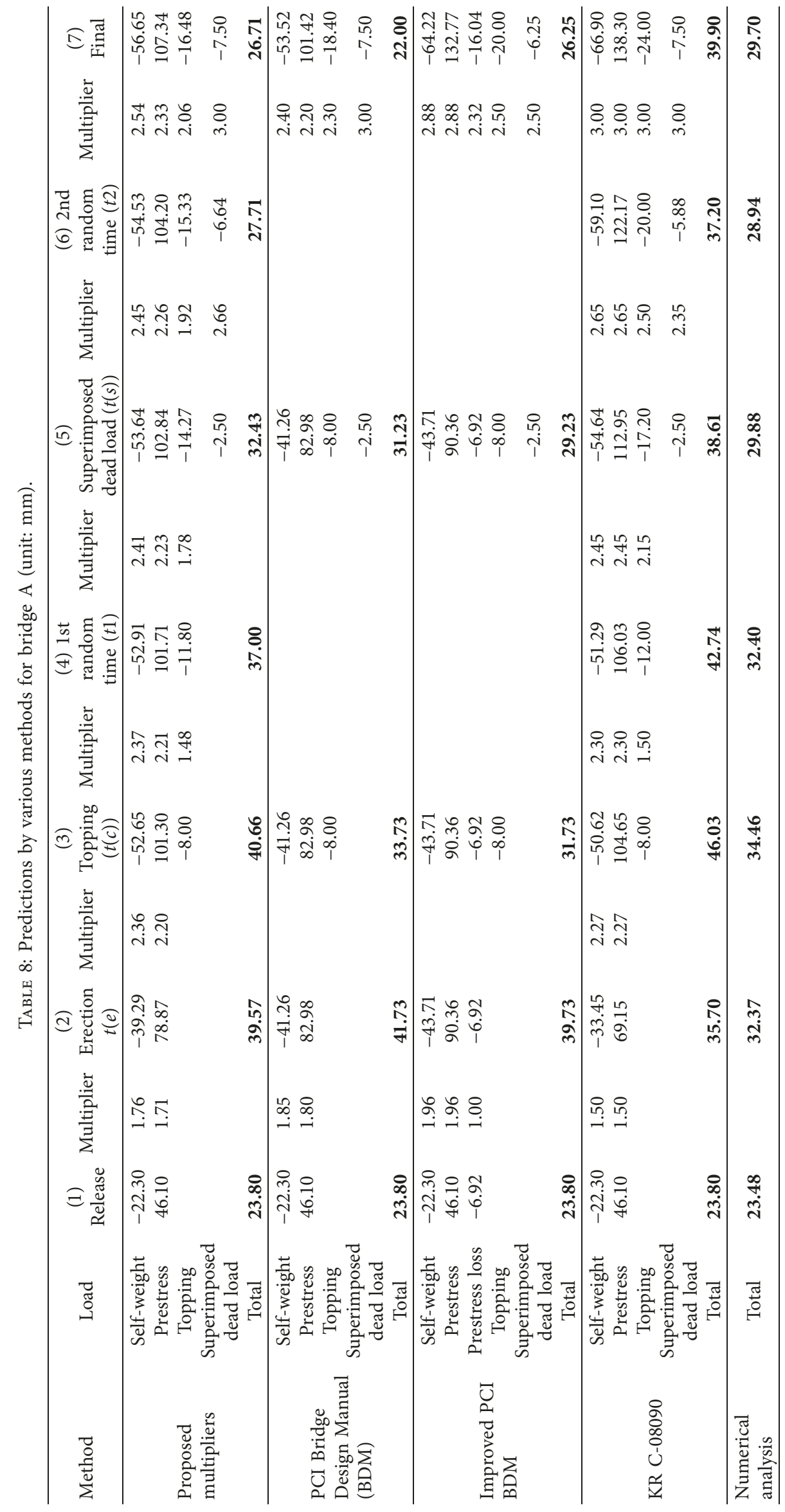




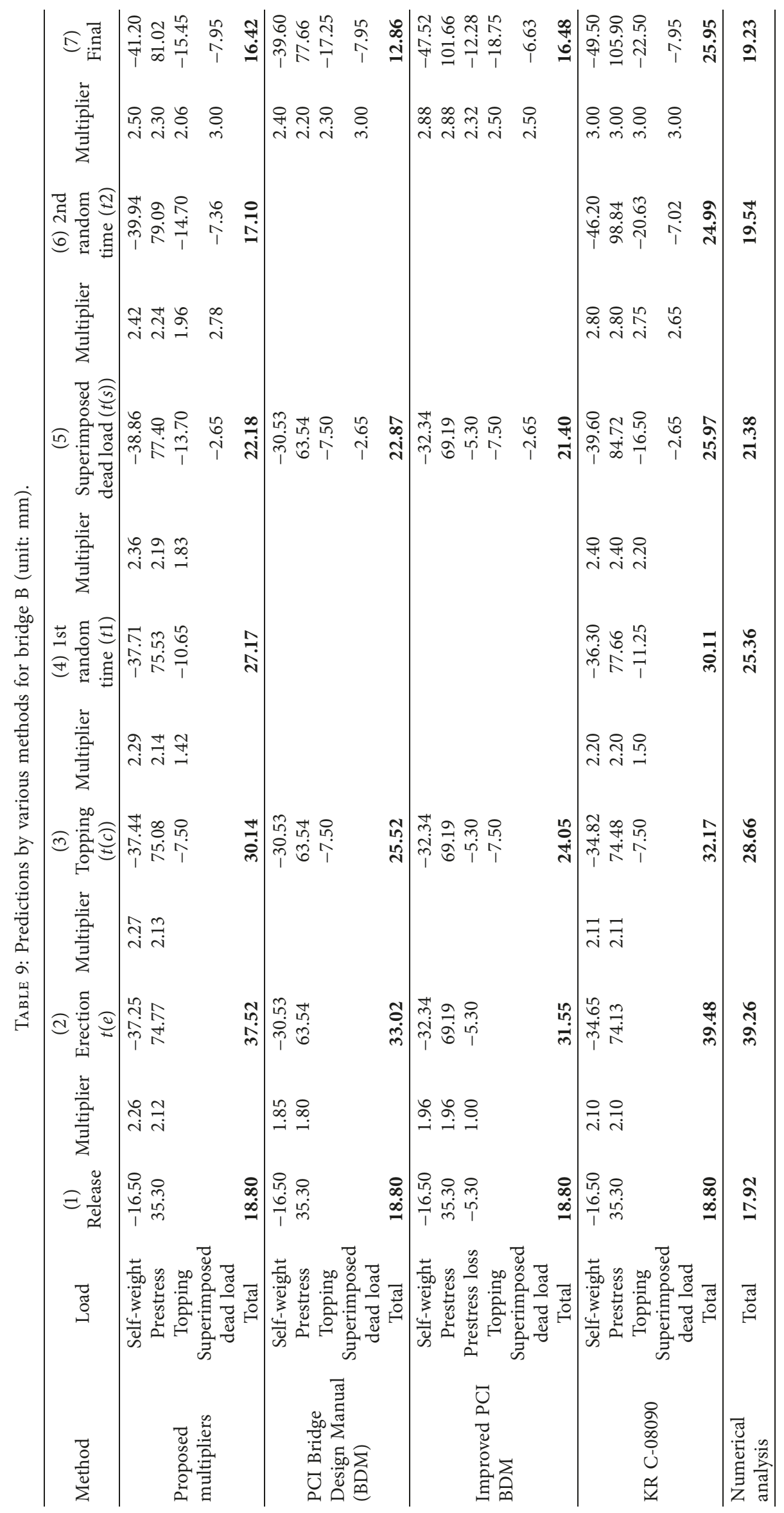




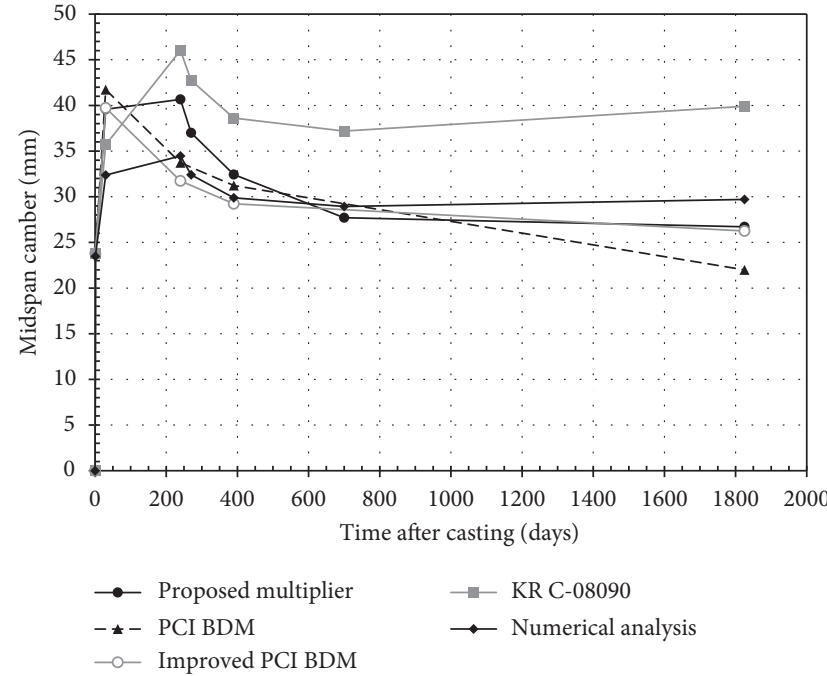

(a)

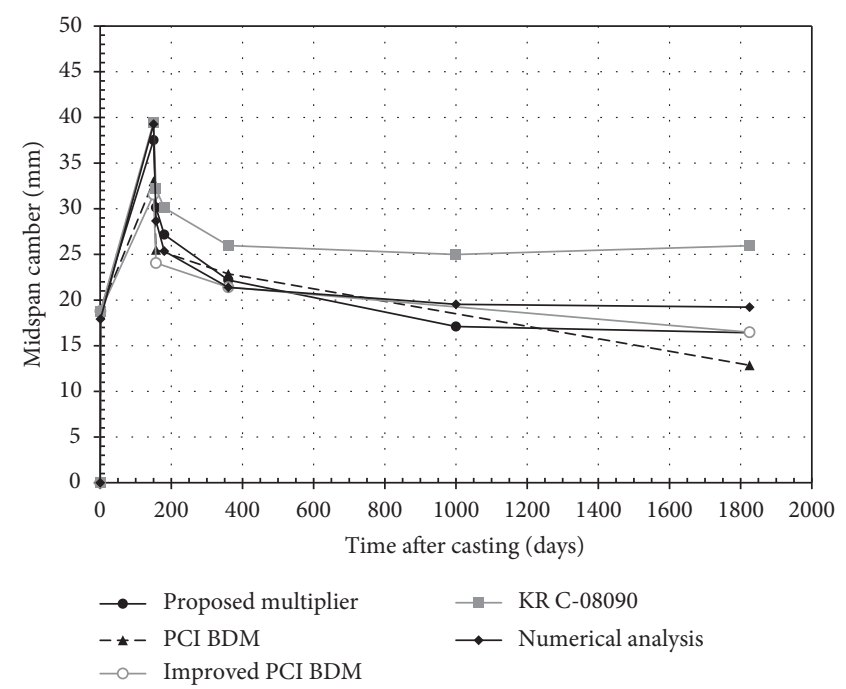

(b)

FIgURE 5: Comparison of various predictions for bridges (a) A and (b) B.

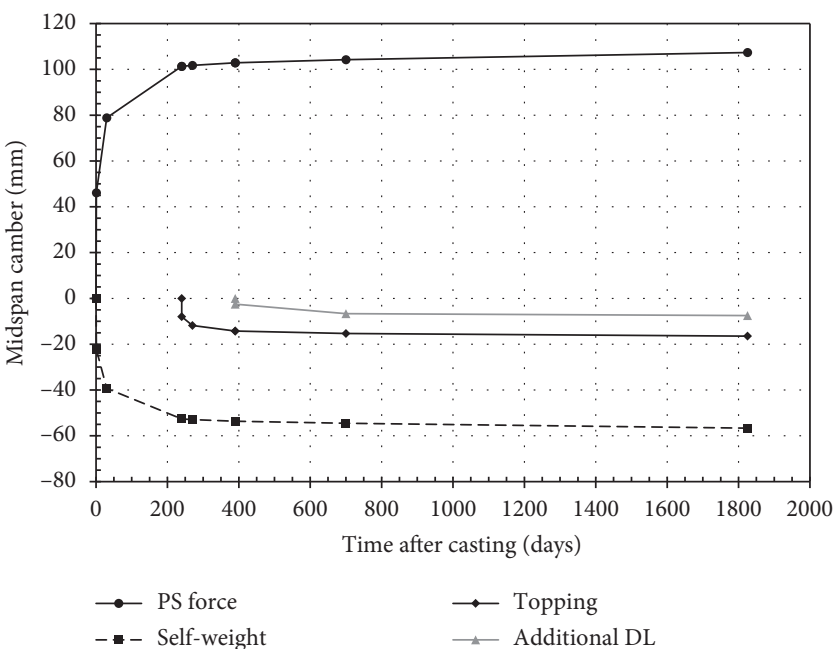

(a)

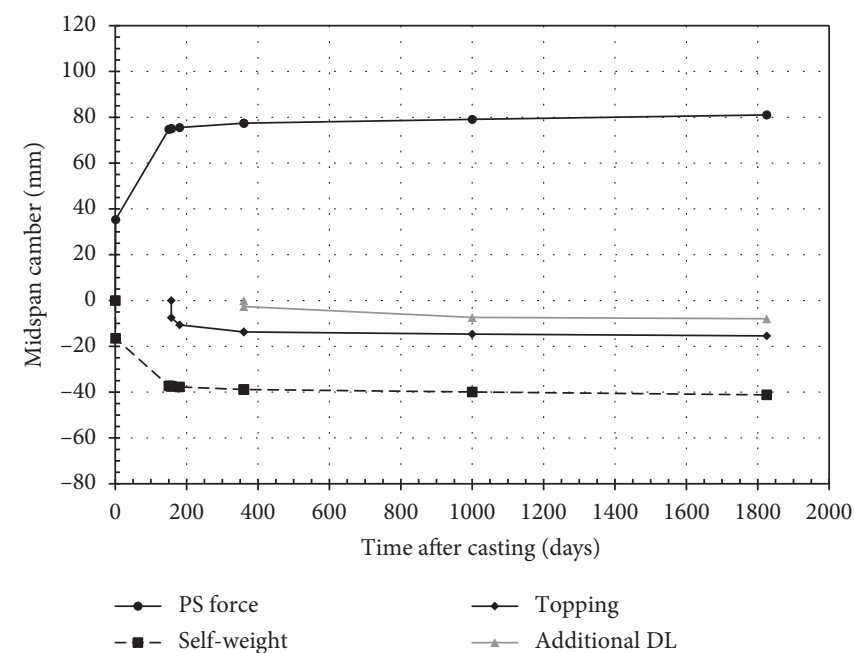

(b)

Figure 6: Predictions by the proposed multipliers for each load type. (a) Bridge A. (b) Bridge B.

Consequently, the proposed multipliers method provided not only the closest prediction values but also the most similar long-term behavior trend to the numerical analysis.

\section{Conclusions}

Since the current PCI Bridge Design Manual [18] provides the long-term deformation multipliers only at erection and final, it cannot consider various construction processes. Furthermore, the multipliers for the composite cross section are also required to be modified to reflect the characteristics of the cross section used in modern PSC bridges. Therefore, in this study, new modified PCI multipliers were proposed to overcome these problems. The conclusions drawn from this study are as follows:
(1) The new modified PCI multipliers were proposed by using the rate of creep and shrinkage over time. Unlike the existing PCI Bridge Design Manual [18] method, it is possible to reflect the actual girder erection time and predict the long-term deformation for any construction schedule. Moreover, through the new method, camber and deflection of PSC bridges can be predicted at any time including design stage, construction stage, and use stage.

(2) The ratio of noncomposite to composite moments of inertia, $I_{\mathrm{o}} / I_{\mathfrak{c}}$, was $0.51-0.56$ as a result of analyzing representative cross sections used in practice by span, while the PCI Bridge Design Manual [18] suggests 0.65 of $I_{\mathrm{o}} / I_{\mathrm{c}}$. Therefore, it is suggested to use the average value of 0.53 for $I_{\mathrm{o}} / I_{\mathrm{c}}$ in order to predict the long-term behavior of composite members. 
(3) In order to verify the proposed multipliers, for actually constructed PSC bridges, the predictions of long-term camber and deflection by the proposed multipliers were compared with those by the basic PCI multipliers [18], improved PCI multipliers [20], KR C-08090 [1], and numerical analysis. As a result, KR C-08090 [1] predictions were significantly higher than the other predictions, and the basic PCI multipliers [18] did not show a reasonable tendency in the long-term behavior between the erection time and the final. Among all methods except the proposed method, the improved PCI multipliers [20] showed the most similar predictions to the numerical analysis. However, this improved PCI multiplier method also has limitations in finding the long-term deflection or camber of the bridge at any time, and there are several variables such as the creep coefficient that must be known precisely, in order to use the multipliers, which is inconvenient for designers to use. However, the predictions through the newly proposed multipliers showed a reasonable long-term behavior trend, and the amount of the final camber was also the most similar to the numerical analysis result. Above all, the proposed method can make it possible for the designer to predict the long-term behavior of the bridge very easily according to any construction schedule.

\section{Data Availability}

The data used to support the findings of this study are available from the corresponding author upon request.

\section{Conflicts of Interest}

The authors declare that they have no conflicts of interest.

\section{Acknowledgments}

This research was supported by a grant (17RTRP-B06791905) from Railroad Technology Research Program funded by Ministry of Land, Infrastructure and Transport of Korean government.

\section{References}

[1] Korea Rail Network Authority, Railway Design Guidelines and Handbooks: Bridge Concrete Track Ends Usability Review (KR C-08090), in Korean, Korea Rail Network Authority, Daejeon, Republic of Korea, 2014.

[2] ACI Committee 318, Building Code Requirements for Structural Concrete (ACI 318-14) and Commentary, American Concrete Institute, Farmington Hills, MI, USA, 2014.

[3] ACI Committe 209, Prediction of Creep, Shrinkage and Temperature Effects in Concrete Structure, American Concrete Institute, Farmington Hill, MI, USA, 1992.

[4] AASHTO (American Association of State Highway and Transportation Officials), AASHTO LRFD Bridge Design Specifications, AASHTO, Washington, DC, USA, 2007.

[5] CEB/FIP, Model Code, Comit Euro-International du Beton, Telford Ltd., London, UK, 1990.
[6] H.-G. Kwak and Y.-J. Seo, "Long-term behavior of composite girder bridges," Computers and Structures, vol. 74, no. 5, pp. 583-599, 2000.

[7] H. Yang, "Uncertainty and updating of long-term prediction of prestress forces in PSC box girder bridges," Computers and Structures, vol. 83, no. 25-26, pp. 2137-2149, 2005.

[8] S. Biswal and A. Ramaswamy, "Uncertainty based model averaging for prediction of long-time prestress losses in concrete structures," Construction and Building Materials, vol. 153, pp. 469-480, 2017.

[9] W. He and Z. Zhang, "Modeling creep fracture in rock by using kelvin discretized virtual internal bond," Advances in Civil Engineering, vol. 2018, Article ID 8042965, 8 pages, 2018.

[10] Y.-S. Park, Y.-H. Lee, and Y. Lee, "Description of concrete creep under time-varying stress using parallel creep curve," Advances in Materials Science and Engineering, vol. 2016, Article ID 9370514, 13 pages, 2016.

[11] Z. Pan and S. Meng, "Three-level experimental approach for creep and shrinkage of high-strength high-performance concrete," Engineering Structures, vol. 120, pp. 23-36, 2016.

[12] H.-G. Kwak and Y.-J. Seo, "Numerical analysis of timedependent behavior of pre-cast pre-stressed concrete girder bridges," Construction and Building Materials, vol. 16, no. 1, pp. 49-63, 2002.

[13] I. N. Robertson, "Prediction of vertical deflections for a longspan prestressed concrete bridge structure," Engineering Structures, vol. 27, no. 12, pp. 1820-1827, 2005.

[14] T. Lou, S. M. R. Lopes, and A. V. Lopes, "A finite element model to simulate long-term behavior of prestressed concrete girders," Finite Elements in Analysis and Design, vol. 81, pp. 48-56, 2014.

[15] P. Liu, Q. Xing, D. Wang, and M. Oeser, "Application of linear viscoelastic properties in semianalytical finite element method with recursive time integration to analyze asphalt pavement structure," Advances in Civil Engineering, vol. 2018, Article ID 9045820, 15 pages, 2018.

[16] A. Sagara and I. Pane, "A study on effects of creep and shrinkage in high strength concrete bridges," Procedia Engineering, vol. 125, pp. 1087-1093, 2015.

[17] H. Sousa, J. Bento, and J. Figueiras, "Construction assessment and long-term prediction of prestressed concrete bridges based on monitoring data," Engineering Structures, vol. 52, pp. 26-37, 2013.

[18] PCI, Bridge Design Manual, Second Release, Precast/ Prestressed Concrete Institute, Chicago, IL, USA, 3rd edition, 2014.

[19] L. D. Martin, "A rational method for estimating camber and deflection of precast prestressed members," PCI Journal, vol. 22, no. 1, pp. 100-108, 1977.

[20] PCI, Bridge Design Manual, Precast/Prestressed Concrete Institute, Chicago, IL, USA, 2nd edition, 2003.

[21] M. K. Tadros, A. Ghali, and A. W. Meyer, "Prestressed loss and deflection of precast concrete members," PCI Journal, vol. 30, no. 1, pp. 114-141, 1985.

[22] Y. Zhang, "Orthogonal test analysis on influencing factors of prestressed concrete small box beam camber," Applied Mechanics and Materials, vol. 405-408, pp. 1527-1530, 2013.

[23] Y. Jianjun, W. Xun, and H. Xianzheng, "Effects of live load on the deflection of long-span PC continuous rigid-frame highway bridge based on midas," in Proceedings of 2014 7th International Conference on Intelligent Computation Technology and Automation, pp. 944-946, Changsha, China, 2014. 
[24] T. Grigorjeva, A. Juozapaitis, and Z. Kamaitis, "Static analysis and simplified design of suspension bridges having various rigidity of cables," Journal of Civil Engineering and Management, vol. 16, no. 3, pp. 363-371, 2011.

[25] ACI Committee 435, Control of Deflection in Concrete Structures, ACI 435R-95, ACI, Farmington Hills, MI, USA, 2003.

[26] F. B. Angomas, "Behavior of prestressed concrete bridge girders," All Graduate Theses and Dissertations, Utah State University, Logan, UT, USA, 2009.

[27] E. H. Gheitanbaf, "Improving the prediction of timedependent effects on prestressed concrete bridges," Graduate Theses and Dissertations, Iowa State University, Ames, IA, USA, 2015.

[28] M. K. Tadros, F. Fawzy, and K. Hanna, "Precast, prestressed girder camber variability," PCI Journal, vol. 56, no. 1, pp. 135-154, 2011. 


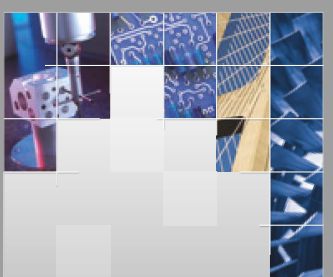

\section{Enfincering}
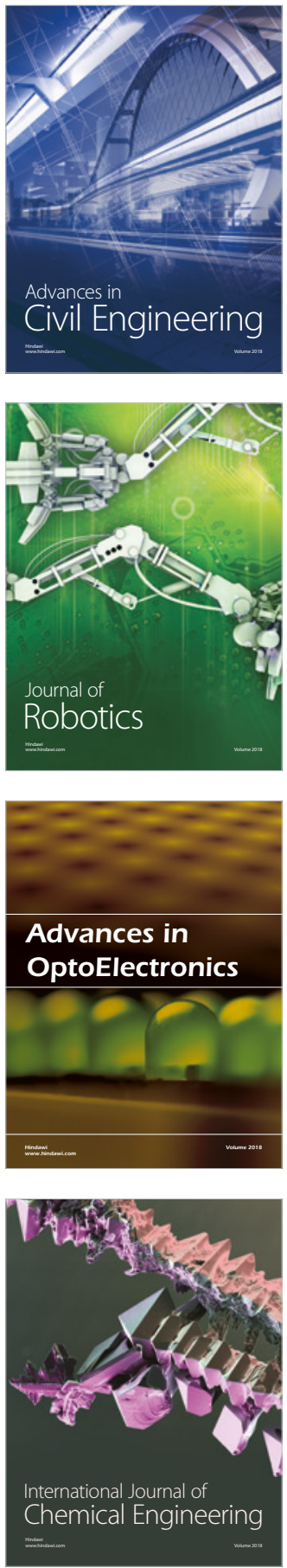

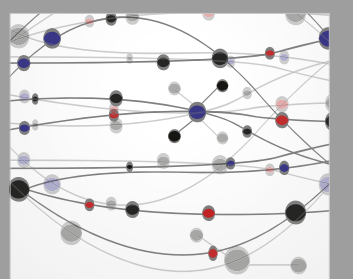

\section{Rotating \\ Machinery}

The Scientific World Journal

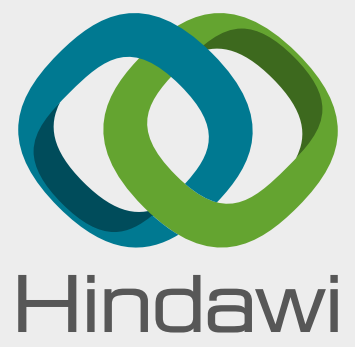

Submit your manuscripts at

www.hindawi.com
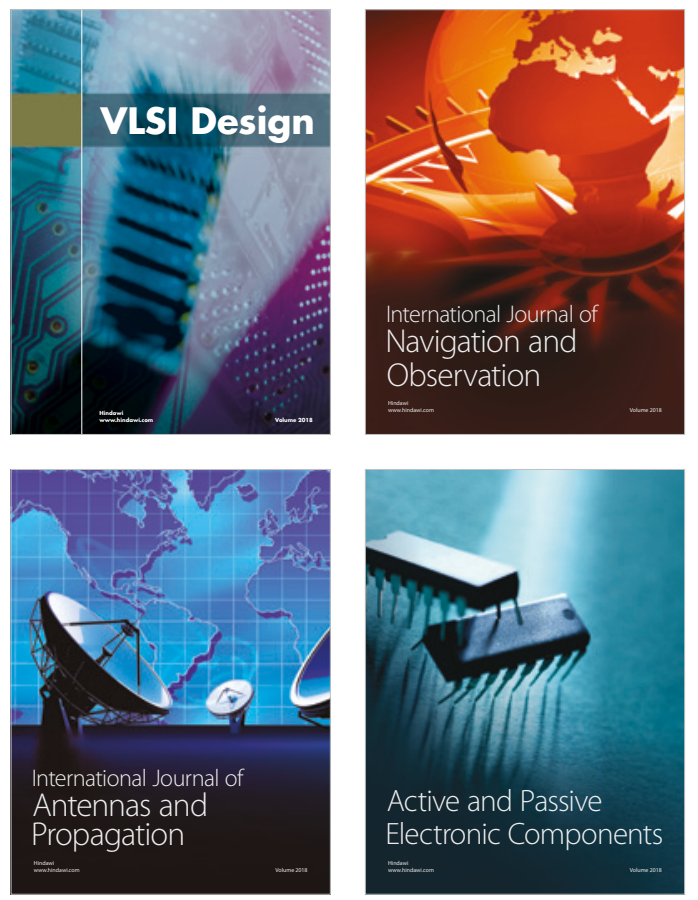
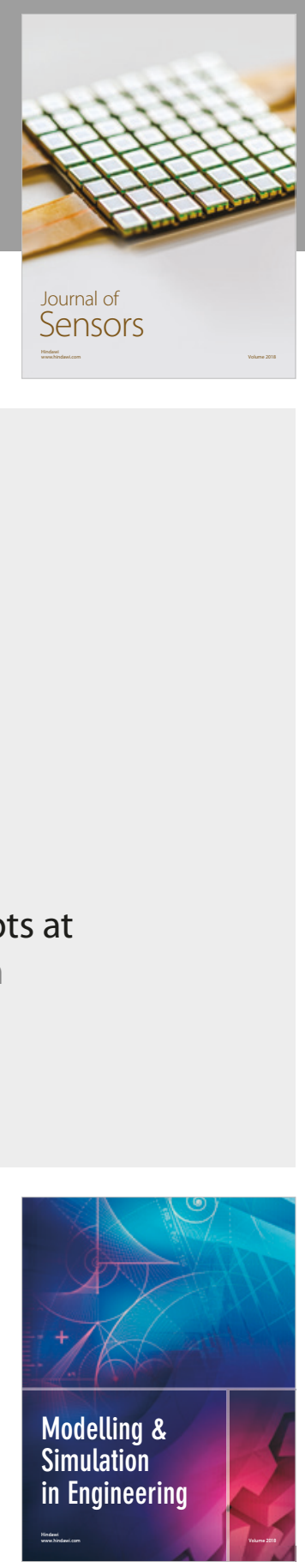

\section{Advances \\ Multimedia}
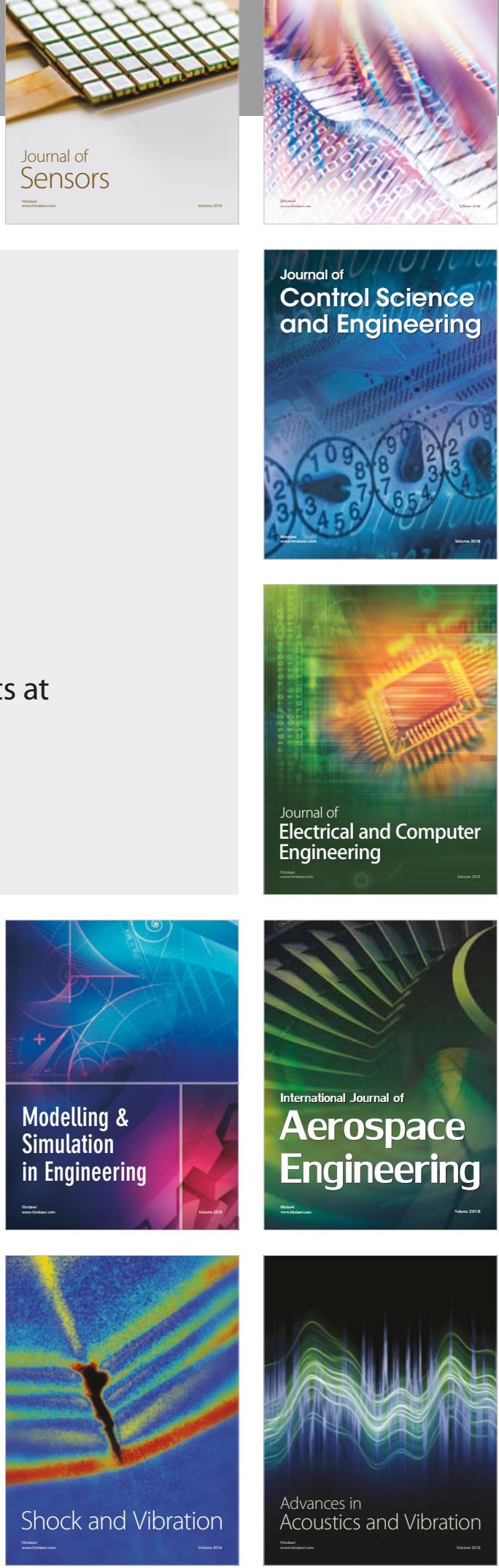